\title{
Amniotic band syndrome: a report of two cases and review of the literature
}

\author{
*Oliemen Peterside, ${ }^{1}$ James E Omietimi, ${ }^{2}$ Oyedeji O Adeyemi ${ }^{1}$ \\ ${ }^{I}$ Department of Paediatrics and Child Health, ${ }^{2}$ Department of Obstetrics and Gynaecology, Niger Delta \\ University Teaching Hospital, Okolobiri, Bayelsa State, Nigeria.
}

\begin{abstract}
Amniotic band syndrome (ABS), also known as Streeter's dysplasia refers to a continuous spectrum of manifestations due to intra-uterine rupture of amnion. ${ }^{1}$ The manifestations range from simple soft tissue constrictive bands to amputation of digits or more severely the whole limb due to dysplastic vasculature. ${ }^{1}$ The prevalence is estimated to be about 7.7/10,000 live births ${ }^{2}$ and as high as 178/10,000 among abortuses. ${ }^{3}$ We herein present two cases of amniotic band syndrome seen at theNiger Delta University Teaching Hospital(NDUTH) with the aim of highlighting its existence in the State as well as throwing light on the prenatal diagnostic challenges and the socio-economic problems faced by families living with physical disabilities.
\end{abstract}

Key words: amniotic band syndrome, case, constriction band, ultra sound scan

\section{Introduction}

Amniotic bands are congenital constriction bands which occur due to rupture of amniotic membrane usually before 12 weeks of gestation. ${ }^{4}$ As the fetus develops, amniotic bands can trap extremities causing immobilization, constriction or even amputation of the structure. ${ }^{4}$ Results of amnion rupture are external so no internal anomalies are associated. ${ }^{5}$ Associated defects include hydra-anencephaly, porencephaly, craniofacial abnormalities and spinal dysraphism. ${ }^{6}$ Most cases are sporadic with no recurrence in siblings of affected patients. ${ }^{7}$ The prevalence is estimated to be about 7.7/10,000 live births ${ }^{2}$ and as high as 178/10,000 among abortuses. ${ }^{3} \mathrm{ABS}$ occurs in $77 \%$ of fetuses with multiple anomalies. ${ }^{8}$ Males and females are equally affected. ${ }^{7}$ Onyinbo et $\mathrm{al}^{9}$ in Bayelsa State, Nigeria reported a prevalence of 3\% among children while Bakare et $\mathrm{al}^{10}$ in South Western Nigeria reported ABS as constituting $0.16 \%$ of all external birth defects found in IfeIjesha from August 2003 to July 2004.Till date there has been no case report of ABS in Bayelsa State in the Delta region of Nigeria. We therefore report two cases seen in the neonatal period with the aim of highlighting its existence in this region.

Case 1

Baby DO was a two hour old male referred to the Paediatrics Department from the Obsterics and Gynaecology Department of the Niger Delta University Teaching Hospital (NDUTH), Bayelsa State. He was referred on account of limb deformities noticed at birth.

He was noticed to have complete absence of the entire left lower limb from the hip down, with constriction rings of the right mid arm and left upper limb digits.

Pregnancy was supervised at the NDUTH from 15 weeks gestation. Mother was regular with her antenatal visits and took only routine antenatal drugs. Mother had a febrile illness at 15 weeks gestation for which she was admitted and treated for malaria with intravenous quinine. She was HIV negative and ultra-sound scan (USS) done at this time showed an active fetus with no detectable structural anomaly. Pregnancy was carried to 37 weeks. Mother drained liquor for about 48 hours prior to delivery. Labour was induced with intra vaginal misoprostol and this resulted in vaginal delivery. Child's birth weight was $2.4 \mathrm{~kg}$, length was $46 \mathrm{~cm}$, APGAR scores were 7 and 9 in one and five minutes respectively.

He was the second child of his parents in a monogamous setting. Mother was a 27 year old petty trader with secondary education while father was a 27 year old applicant with secondary education. His elder sister, a 2 year old female had no obvious structural defect. There was no history of parental consanguinity.

On examination, he had a constrictive band on the proximal third of the right arm and bases of the proximal phalanges of the index, middle and ring fingers of the left hand. There was complete absence of the left lower limb from the hip downwards (figure 1). All other systems were essentially normal.

He was managed as a case of amniotic band syndrome. His parents were counseled and he was reviewed by the Orthopaedics and Plastic Surgeons. Echocardiographic studies showed no structural heart defect while skeletal survey showed that the bones were not affected. The constrictive bands of the upper limbs were released by the Plastic Surgeon after which he was discharged home to come back for follow up. 
At 3 weeks of age during the first follow up visit, mother said child had never been carried by other relatives or visitors and he was always wrapped up because she did not want anyone to see his deformities. At seven months of age, he was brought again to the hospital with a febrile illness and rash. His mother admitted that he had never been immunized as she was afraid he would be stigmatized by other mothers at the immunization clinic if she undressed him to be weighed. He was treated for the febrile illness and his mother was counseled. Parents are currently looking for financial aid to take him to a centre where he can have prosthesis for his lower limbs.

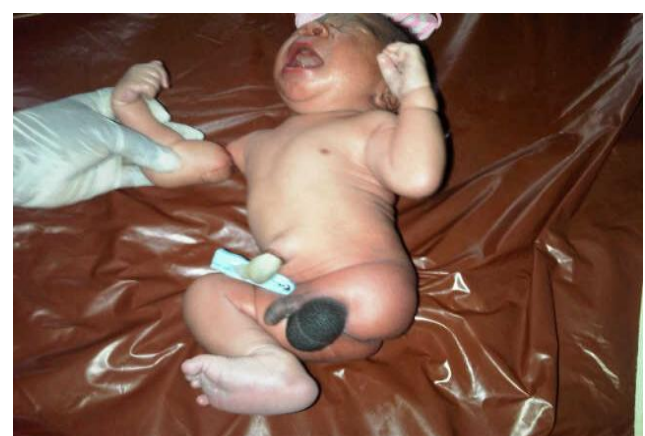

Figure 1: baby with absent left lower limb and constriction ring on the right arm

\section{Case 2}

Baby OG wasa male neonate admitted into the NDUTH on the second day of life on account of swelling and darkish discoloration of the right forearm from birth.

Pregnancy was supervised at the Federal Medical Centre Yenagoa. Mother was regular at antenatal visits and took only routine antenatal drugs. Pregnancy was uneventful and obstetric ultra sound scan done at twenty six weeks gestation showed no foetal abnormality. Delivery was unsupervised at home and was by spontaneous vaginal, the baby cried immediately after birth.

He was the second child in a monogamous family of non-consanguineous parents. There was no family history of limb deformities. His mother was a 27 year old seamstress and his father a 29 year old taxi driver.

On examination, he was a term neonate with a constriction band at the proximal third of the right forearm with gangrene of the forearm distal to the constriction band (figure 2). There was syndactyly of left index, middle and ring fingers (figure 3) as well as the left medial four toes (figure 4). He was febrile with a temperature of $38.7^{0} \mathrm{C}$ and had mild jaundice.

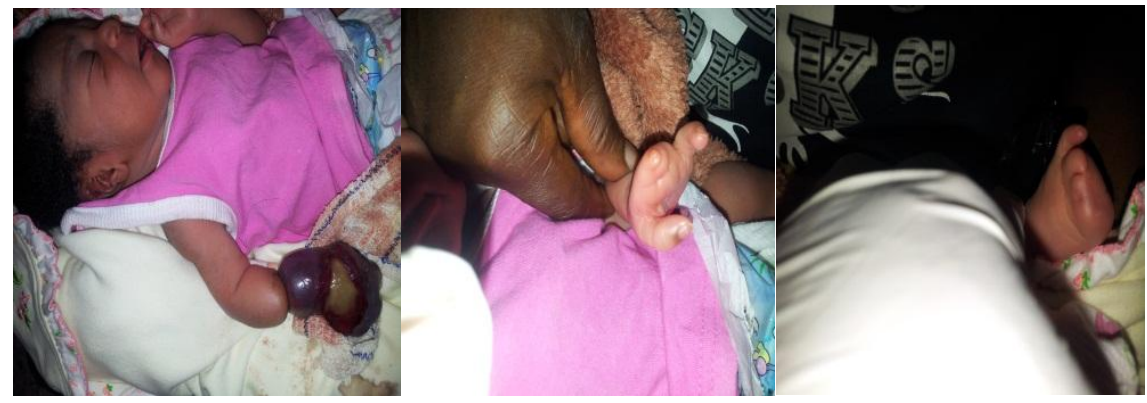

Figure 2: gangrenous right forearmFigure 3: left handFigure 4: left foot

He was managed as a case of amniotic band syndrome with gangrene of the right forearm with jaundice and presumed sepsis. He had a below elbow amputation of the gangrenous limb (figure 5), had phototherapy and intravenous antibiotics. He was discharged in good clinical state of health on the twelfth day of admission and is presently being followed up. 


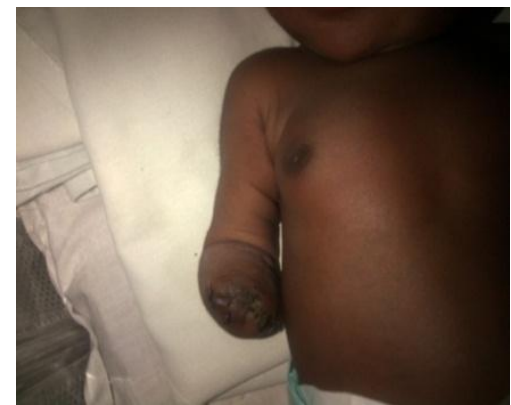

Figure 5: amputated right forearm

\section{Discussion}

Amniotic bands, also called constriction bands, congenital rings, Streeter dysplasia and annular defects are anomalous bands that encircle either partially or completely, a digit or an extremity. ${ }^{11}$ The index cases presented with constriction bands on the right arm and right forearm respectively. Although several theories have been proposed to explain the genesis of ABS, the most widely accepted view is that early rupture of the amnion results in mesodermic bands that emanate from the chorionic side of the amnion and insert on the foetal body, leading to constrictions, amputation and post natal deformities secondary to immobilization. ${ }^{12}$ Young et $\mathrm{al}^{13}$ reported three case of ABS in conjunction with connective tissue disorders. They hypothesized that the amniotic bands may have resulted from premature rupture of the amnion due to reduced or abnormal collagen in the amnion itself.Mahmood NAA, ${ }^{14}$ followed up three pregnant women with USS prenatal diagnosis of ABS. He reported that all three women presented with oligohydramnios suggestive of amniotic rupture. Though Lockwood et $\mathrm{l}^{15}$ suggested the role of a teratogenic insult as one of the causative factors of ABS, in the index cases, there was no history of maternal exposure to teratogens before or during pregnancy. According to Pattersons ${ }^{16}$ diagnostic criteria for ABS, there should be presence of at least one of the following: 1) simple ring constrictions, 2) ring constrictions with distal deformity plus or minus lymph oedema, 3) ring constrictions accompanied by syndactyly or acrosyndactyly, 4) amputation. The index cases fulfilled the above criteria with the first case having simple ring constriction with amputation while the second case had simple ring constriction with distal limb gangrene as well as syndactyly.

From previous studies ${ }^{17-19}$ the most frequent organs involved in ABS are the fingers and toes with or without association with cleft lip and palate. The index cases had finger involvement but without any associated cleft. Internal organ anomalies in infants with ABS are rare ${ }^{7,20-21}$ as was the case in both index cases who had no internal organ involvement. Higginbottom et $\mathrm{al}^{20}$ found that early insult (before 45 days gestation) produced severe facial clefts and severe defects of the brain and calvarium, while late insult (after 45 days gestation) results in limb involvement with no facial clefting or central nervous system involvement. The index cases probably resulted from late insult as they had only limb involvement. Unlike the index cases, other authors ${ }^{22-25}$ have reported more severe cases with associated facial clefts and central nervous system involvement. As in the index cases, Askins and $\mathrm{Ger}^{26}$ found that the distal extremities were most often affected while Foulkes and Reinker $^{27}$ reported that in their seventy year review of ABS, a third of their seventy one patients had lower limb involvement. Musculoskeletal disorders commonly associated with ABS include club foot, syndactyly (as seen in the second case) or acrosyndactyly, hypoplastic nails or fingers, pseudoarthrosis of underlying bones, peripheral nerve defects, distal lymph oedema, intra-uterine amputations (as seen in the first case), cleft lip and palate and umbilical hernia. ${ }^{28} \mathrm{As}$ in the first case, Herrara et $\mathrm{al}^{29}$ also reported a case of ABS with amputation of the right leg while Adeosun et $\mathrm{al}^{25}$ in Maiduguri, Northern Nigeria reported two cases with amputation of the fingers and toes.

Early detection of ABS in utero is not only important for counseling but also for possible intra-uterine surgical repair. ${ }^{30}$ In utero, with the use of obstetric ultra sound scan, amniotic bands can be seen as linear echoes floating in the amniotic fluid and connected to the foetal body. ${ }^{31}$ In the index cases however, the diagnosis of ABS was missed by obstetric ultra sound scan done at 15 weeks and 26 weeks respectively. Jabor and Cronin ${ }^{17}$ in Houston, Texas, USA reported a similar case of a child born with absence of the right lower leg and right arm with cleft lip and palate. While pre-natal USS at thirty nine weeks recognized the cleft lip and palate, it failed to appreciate the limb deformities. Manchester et $\mathrm{al}^{32}$ found $37 \%$ of prenatal USS to be incomplete, with the infant showing additional deformities at birth that were not previously diagnosed. Factors which affect accuracy of USS include: a) timing and duration of examination, b) expertise of the operator, c) technical difficulties such as oligohydramnios, maternal obesity, multiple gestation and multiple malformations. ${ }^{33}$ This highlights the need for training and re-training of Radiologists performing USS in order to improve their diagnostic skills. Nardozza et $\mathrm{al}^{34}$ proposed that three-dimensional USS at the end of the first or beginning of the second trimester enables better comprehension of this pathologic condition. In the second case, in utero diagnosis and surgical repair of 
the constriction band may have prevented the limb gangrene. Ashish and Poonam ${ }^{35}$ in Ambali city India reported a case of a one year old male who had constrictive circumferential grooves just above his left ankle with oedema distal to the constriction. Surgical excision of the fibrous bands on the leg and foot resulted in subsequent normal development of the extremity distal to this band.

The social problems of having a child with disability were highlighted in the first case with his mother denying him of immunization for fear of stigmatization from other mothers at the immunization clinic. She had also given up her trade to care for child herself as she did not want her other relatives to see his deformities. This raises the question of whether this mother would allow her child to go to school. Studies have shown that persons with disabilities have lower educational attainments than persons without disabilities as a result of lower school attendance rates. ${ }^{36-37}$ The child's family is also loosing income as his mother has stopped her trade. This highlights the economic cost of disability as a result of loss of productivity from exits from work or reduced work but fails to highlight the non-economic cost from social isolation and stress which are difficult to quantify ${ }^{38}$ There is an urgent need for the Government to put in place effective programmes for support of individuals and families living with disabilities. In Africa, national studies on living conditions of people with disabilities were conducted between 2001 and 2006 in Malawi, Namibia, Zambia and Zimbabwe. ${ }^{39}$ These studies revealed large gaps in service provision for people with disabilities with unmet needs for welfare, assistive devices, education, vocational training and counseling services.

\section{Conclusion}

Amniotic band syndrome commonly presents with limb deformities which may be prevented with early prenatal diagnosis and surgical intervention. There is need for improvement of diagnostic capabilities of prenatal USS. Families with disabilities resulting from ABS need to be supported to reduce the economic and social consequences.

\section{References}

[1]. Verma A, Mohan S, Kumar S. Late presentation of amniotic band syndrome. A case report. J Clin Diagnos Res 2007; 1(2): 65 - 68.

[2]. Buyse ML. Birth defects encyclopedia. Cambridge (MA): Black Well scientific publications: 1990.

[3]. Seeds JW, Cefalo RC, Herbert WNP. Amniotic band syndrome. Am J Obstet Gynecol 1982; 144: 243.

[4]. Editorial: Amniotic bands. Brit Med J. 1973; 3: 651 - 652.

[5]. Ambika H, Sinjatha C, Santhosh S. Amniotic bands with infantile digital fibromatosis. N Dermatol Online 2011; 2(4): 232 - 233.

[6]. Hata T, Tanaka H, Noguchi. 3D/4D sonographic evaluation of amniotic band syndrome in early pregnancy: a supplement to $2 \mathrm{D}$ ultrasound. J Obstet Gynaecol Res 2011; 37: 656 - 660 .

[7]. Allington NJ, Kumar SJ, Guille JT. Clubfeet associated with congenital constriction bands of the ipsilateral loer extremity. J Pediatr Orthop 1995; 15(5): $599-603$.

[8]. Nyberg DA, Mahony BS, Pretorius DH. Diagnostic ultrasound of fetal anomalies. Littleton (MA): Year book Medical publishers; 1990.

[9]. Oyinbo CA, Dare NW, Amain ED. Prevalence of polydactyly, syndactyly, amniotic band syndrome, cleft lip, cleft palate and talipes equinovarus in Bayelsa State, Nigeria. J Med Inf Biomet Epidemiol 2009; 5(2): 1 - 5.

[10]. Bakare TIB, Sowande OA, Adejuyigbe OO, Chinda Y, Usang UE. Epidemiology of external birth defects in neonates in Southwestern Nigeria. Afr J Paediatr Surg 2009; 6(1): 28 - 30.

[11]. Khan F, Shah SA, Khan NU, Ullah F. Pattern of constriction band syndrome. RMJ 2010; $35(2): 184-187$.

[12]. Torpin R. Amniochorionic mesoblastic fibrous strings and amniotic bands: associated fetal malformations or fetal death. Am J Obstet Gynecol 1995; 91: 95.

[13]. Young ID, Lindenbum RH, Thompson EM, Pembrey ME. Amniotic bands in connective tissue disorders. Arch Dis Child 1985; 60: $1061-1063$.

[14]. Mahmood NAA. Amniotic bands: are they all threat for the fetus? Bahrain Med Bull 2008; 30 (2): 1 - 7.

[15]. Lockwood C, Ghidini A, Romero R. Amniotic band syndrome: re-evaluation of its pathogenesis. Am J Obstet Gynecol 1989; 160: $1030-1033$.

[16]. Patterson TJS. Congenital ring constrictions. Br J Plast Surg 1961; 14: 1 - 31.

[17]. Jabor NA, Cronin ED. Bilateral cleft lip and palate and limb deformities: a presentation of amniotic band sequence? J Craniofac Surg 2000; $11: 388-393$.

[18]. Fiedler JM, Phelan JP. The amniotic band syndrome in monozygotic twins. Am J Obstet Gynecol 1983; $14: 863$ - 864.

[19]. Nyberg DA, Mahony BS, Pretorius DH. Diagnostic ultrasound of fetal anomalies. Littleton (MA): year book Medical Publishers 1990.

[20]. Higgingbottom MC, Jone KL, Hall BD, Smith DW. The amniotic band disruption complex: timing of amniotic rupture and variable spectra of consequent defects. J Pediatr 1979; 95: $544-549$.

[21]. Ossipoff V, Hall BD. Etiologic factors in the amniotic band syndrome: study of 24 patients. Birth defects 1977; $13: 117-132$

[22]. Unsal A, Sezer SD, Meteoglu I, Temocin K, Karanan CZ. Ultrasonographic prenatal diagnosis of isolated acephaly. Diagn Interv Radiol 2007; 13: 196 - 198 .

[23]. Murata T, Hashimoto S, Ishibashi T, Inomata H, Sueishi K. A case of amniotic band syndrome with bilateral epibulbar choristoma. Br J Ophthalmol 1992; 76: 685 - 687.

[24]. Chandran S, Lim MK, Yu-Hei Yu V. Fetal acalvaria with amniotic band syndrome. Arch Dis Child Fetal Neonatol Ed 2000; 82: 11 13.

[25]. Adeosun OO, James O, Akinmoladun VI, Owobu T. Amniotic band syndrome associated with orofacial clefts: a report of two cases. Oral Surg 2012; 5: 185189.

[26]. Askins G, Ger E. Congenital constriction band syndrome. J Pediatr Orthop 1988; 8: 461 - 466.

[27]. Foulkes GD, Reinker K. Congenital constriction band syndrome: a seventy year experience. J Pediatr Orthop 1994; 14 : 242 - 248. 
[28]. Taub PJ, Bradley JP. Typical facial clefting and constriction band anomalies: an unusual association in three related patients. Am $\mathbf{J}$ Med Genet A 2003; 120: 256 - 260.

[29]. Herrera RJH, Martinez YMP, Izaguirre DME. Pseudosyndactyly and amputation as the main features of the amniotic band syndrome. Bol Med Hosp Infant Mex 2011; 68(1): 50 -52.

[30]. Quintero RA, Morales WJ, Phillips J. In utero lysis of amniotic bands. Ultrasound Obstet Gynecol 1997; $10: 316$ - 320.

[31]. Mahony BS, Filly RA, Callen PW. The amniotic band syndrome: antenatal sonographic diagnosis and potential pitfalls. Am J Obstet Gynecol 1985; 152: 63

[32]. Manchester DK, Pretorius DH, Avery C. Accuracy of ultrasound diagnoses in pregnencies complicated by suspected fetal anomalies. Prenat Diagn 1988; 8: 109 - 117.

[33]. Amarante MTJ, Gosain AK, Wadina MS. Bilateral cleft lip and palate associated with agenesis of the hand and distal forearm. J Craniofac Surg 1995; 6: 499 - 501.

[34]. Nadozza LMM, Junior EA, Caetana ACR, Moron AF. Prenatal diagnosis of amniotic band syndrome in the third trimester of pregnancy using 3D ultrasound. J Clin Imag Sci 2012; 2(1): 1 - 3.

[35]. Ashish M, Poonam M. Amnitic band syndrome. Pediatr Oncall 2012; 9(2): doi no 10.7199

[36]. Loeb M. poverty and disability in Eastern and Western Cape Provinces, South Africa. Disability and Society 2008; $23: 311$ - 321.

[37]. Rischewski D. Poverty and musculoskeletal impairment in Rwanda. Transactiona of the Royal Society of Tropical Medicine and Hygiene 2008; 102: $608-617$.

[38]. Mitra S, Findley PA, Sambamoorthi U. Health care expenditures of living with a disability: total expenditures, out-of-pocket expenses and burden, 1996 - 2004. Arch Physic Med Rehab 2009; 90: 1532 -1540.

[39]. South African Federation of the Disabled, Norwegian Federation of Disabled People, SINTEF. Living conditions among people with activity limitation in Southern Africa: representative surveys on living conditions among people with activity limitations in Malawi, Namibia, Zambia, Zimbabwe and Mozambique. Oslo, SINTEF, 2007. 